\title{
Editorial: On IRIE Vol. 28
}

The International Review of Information Ethics (IRIE) was first issued in 2004, co-funded by myself together with Thomas Hausmanninger (University of Augsburg) and Felix Weil, CEO of the software company QUIBIQ (Stuttgart) who hosted the journal. During fifteen years the editors Jared Bielby, Johannes Britz, Michael Nagenborg and Makoto Nakada as well as some sixty members of the Editorial Advisory Board and a plethora of authors from all over the world helped this journal to flourish. It was conceived as the journal of the International Center of Information Ethics (ICIE) created in 1999 to give answers to the ethical challenges of the digital age.

When we started, we could hardly imagine the issues dealt with by IRIE during the following years. I highlight some of them. The contributions to the ICIE Symposium in 2004 led what would become the first symposium discussions dealing with what was later to be called Intercultural Information Ethics. The proceedings were published as vol. 4 of the ICIE book series at Fink (Munich, Germany) in 2007 with the title "Localizing the Internet. Ethical aspects in intercultural perspective". The proceedings of the first African Information Ethics Conference held in 2007 in Pretoria, South Africa, were published in 2007. Vol.13 (2010) was devoted to Intercultural Information Ethics. Vol. 18 (2012) dealt with New ICTs and Social Media: Revolution, CounterRevolution and Social Change. A year later, vol. 20 dealt with Ethics of cyber warfare and volume 24, 2016 with Ethics of Big Data. The last two issues in 2017 and 2018 were devoted to Information Ethics from a Marxian Perspective, and to Ethical Issues of Networked Toys.

The development in the IT field is breath-taking and the topics will continue changing as they did in the last fifteen years. What gives a unity to this diversity of topics is the question on how they impact our self-awareness as individuals and societies, addressing who benefits from these changes towards a better life, and who does not. This was the leading question asked by the start-ups of our field such as Norbert Wiener and Joseph Weizenbaum.

I thank Geoffrey Rockwell and Jared for inviting me to the AI, Ethics and Society Conference organized by the Kule Institute for Advanced Study, University of Alberta held in Edmonton in May 8-10, 2019. It gave me the opportunity to learn from many colleagues and to meet old friends like Soraj Hongladarom (Thailand) from whom I have learnt a lot over the years during a long-standing East-West intercultural dialogue. The organizers invited me to review my paths of thought dealing with AI from the seventies onward, thoughts that I've presented in one of the articles published below in this, the first issue of new IRIE.

I wish Jared Bielby and his team to take the bull by the horns and like Cretan athletes make big leaps in thinking-with-others around the ethical challenges of information technology over the next fifteen years. IRIE and ICIE have found a wonderful new home at the University of Alberta for which I am very thankful.

Sincerely yours,

Rafael Capurro 